\title{
Effects of Rainfall Intensity, Soil Slope, and Geology on Soil Erosion in Korea
}

\author{
Jeong, Gyo-Cheol ${ }^{1}$, Choo, Chang-Oh ${ }^{1}$, Ryu, Jeong-Ok ${ }^{1}$, Cho, Heuy-Nam ${ }^{2}$ \\ ${ }^{1}$ Dept. of Earth and Environmental Sciences, Andong National University \\ Gyeongdongro 1375, Andong, Republic of Korea \\ jeong@anu.ac.kr; mineralogy@hanmail.net; ryujo87@naver.com \\ ${ }^{2}$ G\&G Technology Co., Ltd. \\ Songdo-dong 214, Incheon, Republic of Korea \\ ggpgu@ hanmail.net
}

\section{Extended Abstract}

In recent decades, there has been a growing concern over the soil erosion in Korea which is mostly induced by extreme rainfall during a rainy summer season. Soil erosion is partly associated with landslide or failures of slope where thick soil profile develops. The supply of fine particles to dams and rivers induced by soil erosion causes a critical turbidity composed of suspended matters over a long period. It was shown that landslides induced by debris flow in Korea are commonly related to the geotechnical properties and clay mineralogy of precursor soils developed on bedrock [1]. This study aims to elucidate the importance of geological characteristics, soil slope, and rainfall intensity in relation to soil erosion. The analytical results by XRD show that primary clay minerals contained in the slopes where intensive soil erosion takes place are illite, chlorite, kaolinite, and montmorillonite. It is evident that erosion rates were proportional to rainfall and clay contents. Because illite is the most abundant clay in soil, it serves as one of the most effective factors that induce intensive soil erosion. According to monitoring on field sites, the rates of soil erosion increased with increasing slope angles and precipitation rates. Soil erosion was initially controlled by rill development and original topography. The runoff amounts discharged from soil increased turbidity and clay contents removed, especially high in metamorphic rocks.

This study demonstrated that it is possible to predict a critical depth and the change in the safety factors of a slope subject to rain infiltration and that a rainfall-induced landslide largely depends on clay mineralogy in the soil and slope parameters affecting soil erosion. Environmental management for soil erosion, especially landslide related to significant soil loss, needs systematic observations and monitoring on different lithologies at varying rates of outflow, which can be supported by understanding mechanical properties and clay mineralogy of soils at slopes.

\section{References}

[1] G. C. Jeong, K.S. Kim, C.O. Choo, J.T. Kim, M. I. Kim, "Characteristics of landslides induced by a debris flow at different geology with emphasis on clay mineralogy in South Korea," Nat. Hazards, vol. 59, no. 1, pp. 347-365, 2011. 